\title{
O eco-feedback na interface da lavadora de roupas como estratégia de design para a mudança de comportamento
}

\author{
The eco-feedback in the washing machine interface \\ as a design strategy for behavior change
}

Marcelo S. Forcato, Aguinaldo dos Santos

design para o

comportamento

sustentável, eco-feedback, habitação de interesse social, mudança de comportamento
Este artigo reporta pesquisa que teve como objetivo identificar meta-requisitos para o projeto de eco-feedback em lavadoras de roupas voltadas ao morador de habitação de interesse social (HIS). A suposição é que através da aplicação desta estratégia de design na interface da lavadora ocorra o início de um processo de mudança comportamental. O método de pesquisa consistiu de Pesquisa-ação fundamentada pelo Método RITE (Medlock et al., 2002), que permitiu um processo cíclico de desenvolvimento e avaliação de eco-feedbacks para lavadoras automáticas, envolvendo usuários, pesquisadores e fabricante. Neste artigo será reportado apenas o último Ciclo de Ação, o qual aborda um pré-teste de interação. Dos resultados da pesquisa resulta lista de meta-requisitos para o projeto de eco-feedback para máquinas de lavar roupa.

This article reports research that aimed to identify meta-requisites for the eco-feedback design in washing machines aimed at the social housing. The assumption is that by applying this design strategy in the washer interface it would initiate a process of behavioral change. The research method consisted of Action Research substantiated by RITE Method (Medlock et al., 2002), which allowed a cyclic process of developing and evaluating eco-feedback for automatic washers, involving users, researchers and manufacturer. In this article is reported only the last stage of Action, which discusses an interaction evaluation. The results of the survey results meta-requisites list for the ecofeedback design for washing machines.

\section{Introdução}

O presente trabalho explorou o potencial do eco-feedback em iniciar um processo de mudança de comportamento no morador de habitação de interesse social (HIS). Segundo IPEA (2012), esta população desde 2002 vem passando por rápida ascensão econômica. Isto provocou perceptível alteração em seu poder de compra e em seus hábitos e comportamentos de consumo. Por isso, buscou-se identificar meta- 
requisitos para o projeto de eco-feedback em máquinas de lavar roupas além de avaliar e demonstrar as implicações práticas dos metarequisitos obtidos no comportamento do morador de HIS. Utilizou-se como Modelo para Mudança de Comportamento aquele proposto por Grimley et al. (1997), conforme figura a seguir.

Figura 1 Modelo de Mudança de Comportamento proposto por Grimley et al. (1997).

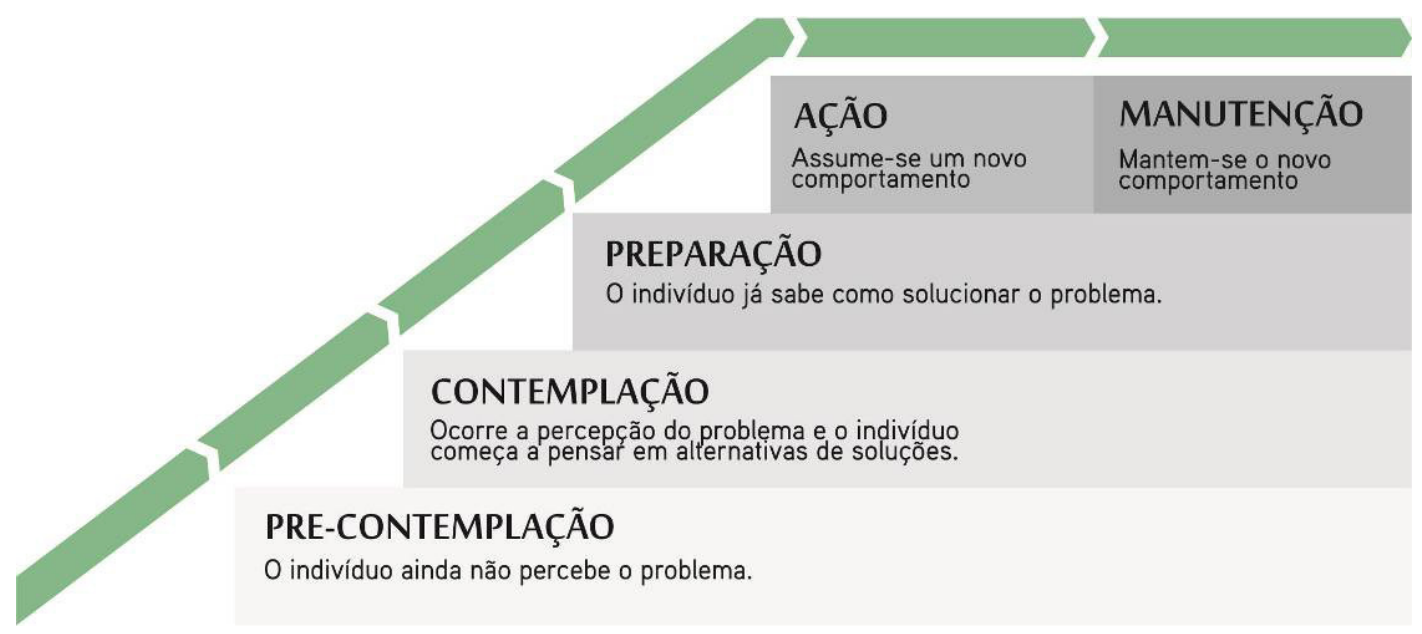

O Design sempre influenciou comportamentos, seja de forma intencional ou não. O foco convencional tem sido no estímulo à ampliação do consumo, ignorando muitas vezes os limites de resiliência do meio-ambiente e as implicações sociais e econômicas negativas das soluções desenvolvidas. Para reduzir tal impacto destaca-se a fase de utilização a qual para muitos produtos é a que apresenta o maior consumo material (Tang \& Bhamra, 2008b). Assim, o "Design para o Comportamento Sustentável" tem como objetivo influenciar o comportamento, principalmente na fase de uso dos produtos, de forma a reduzir os impactos ambientais, econômicos e sociais decorrentes do processo de consumo (Lockton, 2005; Design Council, 2006; Lilley \& Lofthouse, 2009a).

Os hidrômetros e medidores de energia informam o consumo e possibilitam que o usuário acompanhe o consumo de água e energia na habitação. Decorrente do advento de sistemas de medição automáticos e inteligentes tem-se desenvolvido aparelhos com tecnologias que oferecem informações ao usuário. São exemplos destes os Smart Meters e os Smart Grids. Segundo Froehlich (2011), os Smart Meters são sistemas inteligentes de mensuração que fornecem informações sobre os recursos consumidos pelos usuários em suas residências. Já os Smart Grids são sistemas inteligentes de monitoramento que possibilitam a compreensão do usuário dos momentos em que o recurso a ser consumido está mais barato (Falcão, 2009). No entanto, estes exigem esforços dos moradores no sentido de adotar a prática de monitorar seus próprios níveis de consumo. 
Embora esforços estejam sendo feitos através de pesquisas para registrar e fazer levantamentos sobre os impactos relacionados ao consumo de recursos como água e energia, inclusive em eletrodomésticos, as preocupações geralmente se concentram no montante do consumo e não na forma como ele ocorre. Isto provoca uma lacuna entre os dados gerais de consumo e a forma de utilização. Há, portanto, a premente necessidade de melhor compreensão sobre o comportamento real dos usuários bem como a efetividade de estratégias para influenciar o comportamento na direção da sustentabilidade (Tang \& Bhamra, 2008b). Segundo Lockton et al. (2009), relativamente pouco tem sido feito pelos designers para vincular ideias e técnicas do Design Sustentável de forma que possam ser aplicadas durante o processo de inovação visando um comportamento que resulte em consumo mais sustentável.

Compreender o comportamento habitual, ou seja, o que os usuários fazem e como usam os bens duráveis (por exemplo: lavadoras) e bens não duráveis (por exemplo: água e energia), permite ao Designer desenvolver interfaces mais eficazes para produtos e serviços. A tangibilização do consumo pode contribuir na conscientização do usuário em prol de práticas de consumo mais sustentáveis (Tang \& Bhamra, 2008a). Diante deste cenário, percebe-se a necessidade de aprofundar aspectos relativos ao comportamento do usuário (por exemplo: como realiza ou percebe o consumo, o que consome, quanto consome, porque realiza ou utiliza, quando pratica cada ação) com respeito às várias estratégia de Design para o Comportamento Sustentável.

Eco-feedback é uma dessas estratégias. Pode ser entendido como a incorporação de informações em tempo real na interface de produtos e serviços acerca dos níveis de consumo do próprio usuário ou grupo de usuários. A transparência das informações de consumo obtida através do Eco-feedback, somada a outras estratégias complementares, pode contribuir para práticas de consumo mais racionais e responsáveis (Tang \& Bhamra, 2008a; Froehlich et al., 2010). De maneira geral, o eco-feedback pode ser integrado na interface de um produto ou serviço através de dispositivos de comunicação voltados aos sentidos da audição, visão e tato, através de soluções de compreensão instantânea ou soluções que demandem algum tempo para interpretação.

A busca pela elevação ou manutenção do status social faz parte do comportamento humano, mas apesar de seus benefícios psicológicos, via de regra amplia o impacto ambiental do consumo. Pesquisas apontam que as pessoas não conseguem estabelecer uma relação entre as atividades que realizam e os impactos que estas causam (Tang \& Bhamra, 2008b; Lilley \& Lofthouse, 2009b). A inserção de tecnologias de eco-feedback, em lavadoras de roupas, por exemplo, pode oferecer em tempo real ou em um curto período de tempo respostas sobre como as pessoas estão desempenhando a atividade (Froehlich et al., 2010). Assim o eco-feedback na lavadora 
de roupas voltado à população de baixa renda, deve abordar metarequisitos que contemplem as particularidades desta população. Os feedbacks informados devem estar alinhados às posições sociais e econômicas dos moradores de HIS no sentido de conduzir seus comportamentos, através de estratégias de re-educação, à práticas de utilização mais sustentáveis. Presume-se que a aplicação destes metarequisitos no desenvolvimento de eco-feedabaks e sua disponibilização em tipologias de interfaces já pertencentes ao repertório da baixa renda possa contribuir para que este processo de transição comportamental aconteça.

\section{0 eco-feedback como estratégia para mudança comportamental}

No campo do design de interfaces, o eco-feedback é estudado como um subsídio para tentar medir e estimular a mudança de comportamento (Froehlich et al., 2010). A integração do eco-feedback na interface de artefatos baseia-se na hipótese de que grande parte das pessoas não compreendem e/ou não tem consciência de que seus hábitos rotineiros, como ir de carro ao trabalho ou tomar banho prolongado, por exemplo, afetam e causam impacto ao meio ambiente (Tang \& Bhamra, 2008b; Lilley \& Lofthouse, 2009b; Froehlich et al., 2010).

Supõe-se que ao adquirir a informação através do eco-feedback, o usuário passe a se comportar de forma mais consciente (Froehlich et al., 2010). No entanto, Tang \& Bhamra (2008b) argumentam que existe uma lacuna entre a consciência ambiental e a ação real, o que requer estudos mais aprofundados para a compreensão deste problema. Contudo, Normam (2007) e Brewer \& Stern (2005) apud Froehlich et al. (2010) afirmam que para aumentar o potencial de absorção da informação, esta deve ser de fácil compreensão, inspirar confiança, atrair a atenção e estar o mais próximo do tempo e local da ação. Entende-se, portanto, que é possível alcançar como implicações positivas do uso do eco-feedback alguns desejos almejados pela população moradora de HIS, entre os quais: a redução do consumo de recursos; a redução dos gastos com pagamento destes recursos; as melhorias na qualidade de vida; o aumento do tempo disponível para outras atividades; e a própria mudança comportamental no que tange esta atividade.

A construção das relações de causa e efeito entre eco-feedback e comportamento/hábito ainda carece de pesquisas mais profundas, incluindo a avaliação das possíveis consequências negativas. De qualquer forma, é senso comum que o fornecimento de informações sobre o consumo é condição básica para que a ampliação da consciência ambiental das pessoas determine ações e decisões voltadas à sustentabilidade (Tang \& Bhamra, 2008b). 


\section{Método de pesquisa}

Esse estudo foi realizado em duas etapas sendo que a primeira consistiu de Revisão Bibliográfica para a estruturação de conceitos, princípios, métodos e ferramentas associados ao Design para a Sustentabilidade, ao Comportamento Humano e ao Design para o Comportamento Sustentável, tendo o Eco-feedback como foco central da pesquisa. A segunda etapa teve natureza exploratória e consistiu da realização de uma Pesquisa-ação que ocorreu ao longo de quatro ciclos de ação. Estas etapas da Pesquisa-ação foram conduzidas seguindo os preceitos do Método RITE (Rapid Iterative Testing and Evaluation Method). De acordo com Medlock et al. (2002), o Método RITE tem como características gerais o envolvimento do pesquisador com representantes do público pesquisado através de dinâmica que envolve o desenvolvimento, teste e modificação de interface em ciclos curtos. Assim, os quatro ciclos de ação executados nesta pesquisa contemplaram as etapas denominadas "planejamento e preparação", "implementação", "análise" e "ação do próximo ciclo", conforme preconiza a Teoria da Aprendizagem Experiencial de Kolb (1978).

O Ciclo de Ação 01 consistiu de uma survey que teve como foco a coleta de dados demográficos de uma população moradora de HIS sobre sua percepção quanto à atividade de lavar roupas, a percepção sobre o consumo de água e energia, além de entender o fluxo típico da tarefa de lavar roupas adotado. As etapas dos ciclos de ação em que houve envolvimento com o usuário estão ilustradas na imagem a seguir.

Figura 2 Modelo de cartão utilizado no referido ciclo de ação.

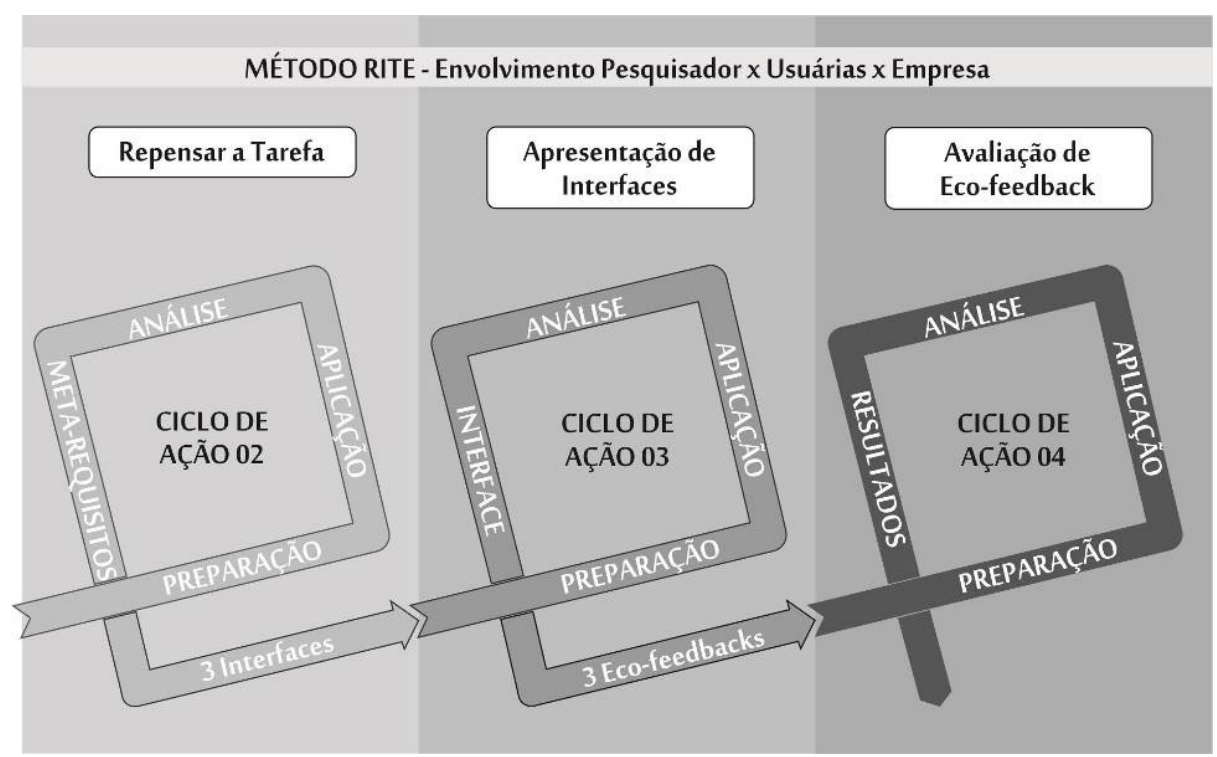

Workshops com designers de empresa fabricante de lavadoras, discussões internas entre os membros do grupo de pesquisa e o confronto dos resultados com a literatura foram as estratégias utilizadas para Validação Externa e Interna. 


\section{Resultados}

Reporta-se neste artigo os resultados obtidos no ciclo de ação quatro da pesquisa-ação. Neste ocorreu um pré-teste de interação das usuárias com três tipologias de eco-feedback inseridos em um mockup de lavadora. O objetivo deste ciclo de ação foi entender se a percepção sobre as informações de consumo exibidas em um processo de simulação do eco-feedback incitou os usuários a refletirem sobre o comportamento de utilização e consumo. Com isso, obteve-se como resultado, meta-requisitos para o design de eco-feedback em lavadoras utilizadas por população de baixa renda, além das percepções acerca dos estágios iniciais de mudança de comportamento.

\section{Etapa 01: planejamento e preparação}

Esta etapa compreendeu o desenvolvimento de um Script de simulação do processo de lavagem de roupas. Este Script foi transformado em cartões (figura a seguir) que conduziram o usuário em 28 ações durante a experiência.

Figura 3 Modelo de cartão utilizado no referido ciclo de ação.

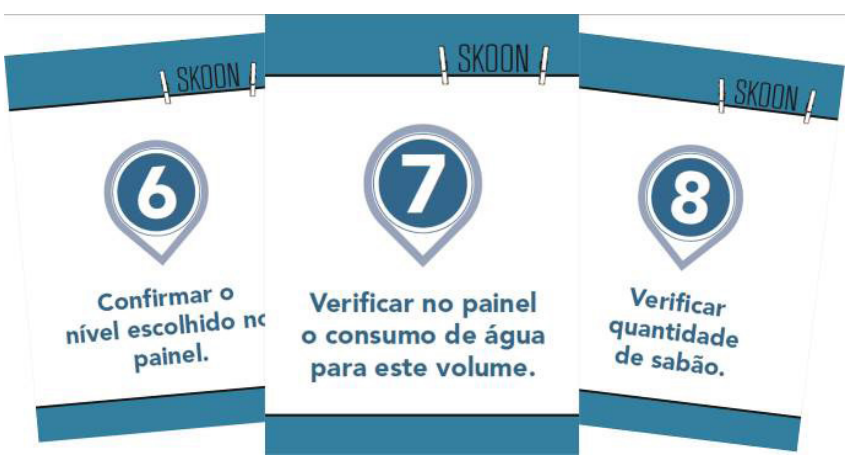

O desenvolvimento do eco-feedback contemplou o desenho de várias telas do display com informações referentes àquelas ações constantes do Script de Simulação do Processo de Lavagem de Roupas. Obteve-se assim 13 telas que apresentaram os resultados da interação com o eco-feedback, as quais ofereciam respostas para cada ação. Três modelos de eco-feedback foram criados adotando tipologias diferentes, porém, com as mesmas informações, conforme figura a seguir. 
Figura 4 Layouts de eco-feedback com informações de lavagem.

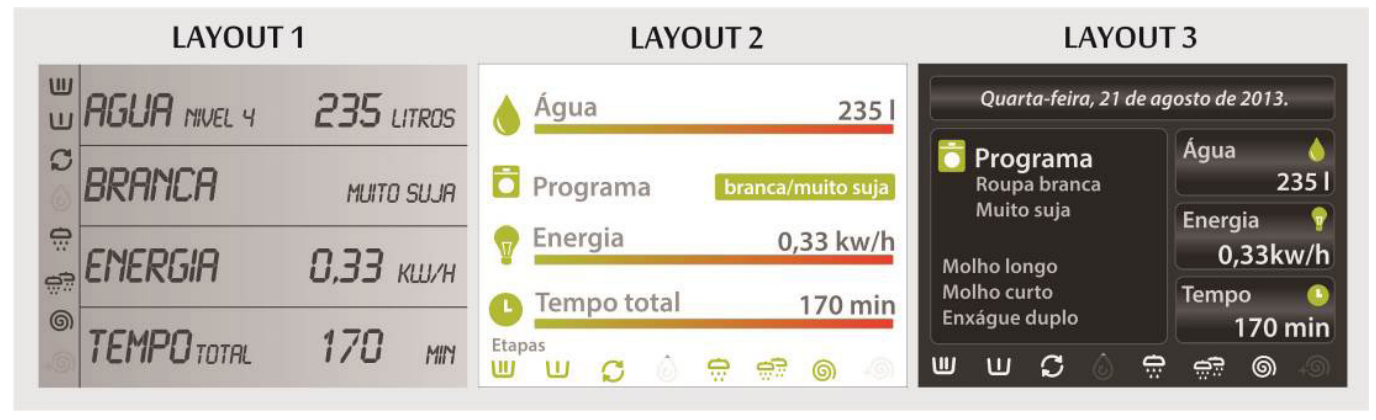

Foi utilizada neste ciclo de ação uma carenagem de lavadora automática, adaptada para receber um smartphone que simulou uma tela de display (figura a seguir), além de câmera fotográfica, filmadora, gravador de áudio e material de anotação.

Figura 5 Carenagem do painel de controle de lavadora adaptado para funcionamento do eco-feedback (mockup).

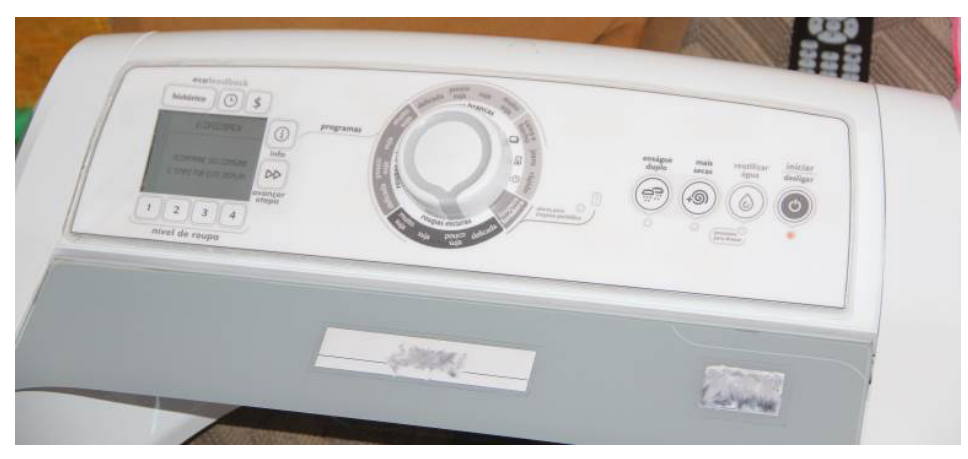

\section{Etapa 02: aplicação}

A atividade foi realizada com duas usuárias, participantes dos Ciclos de Ação anteriores, em suas próprias casas. A usuária 1 possuía uma lavadora automática e a usuária 2 lavava suas roupas em um tanquinho elétrico. Ambas as famílias das usuárias possuíam crianças em idade escolar. As usuárias foram convidadas a simular a atividade de lavar roupas utilizando os cartões e o mockup da lavadora.

No primeiro momento houve o reconhecimento do painel da lavadora (mockup), pelas usuárias, com o layout 1. Em seguida, os cartões com as ações foram entregues às usuárias, um a um. Nestes cartões havia sequência de processo de lavagem específico para roupas brancas muito sujas. A cada cartão disponibilizado, a ação era simulada no mockup da lavadora, ao mesmo tempo em que falavam em voz alta o que estavam fazendo e pensando. O cartão seguinte somente era disponibilizado após a execução da atividade sugerida no cartão. A cada ação as informações eram atualizadas no display por meio do smartphone. 
Figura 6 Usuárias participando do ciclo de ação 4.

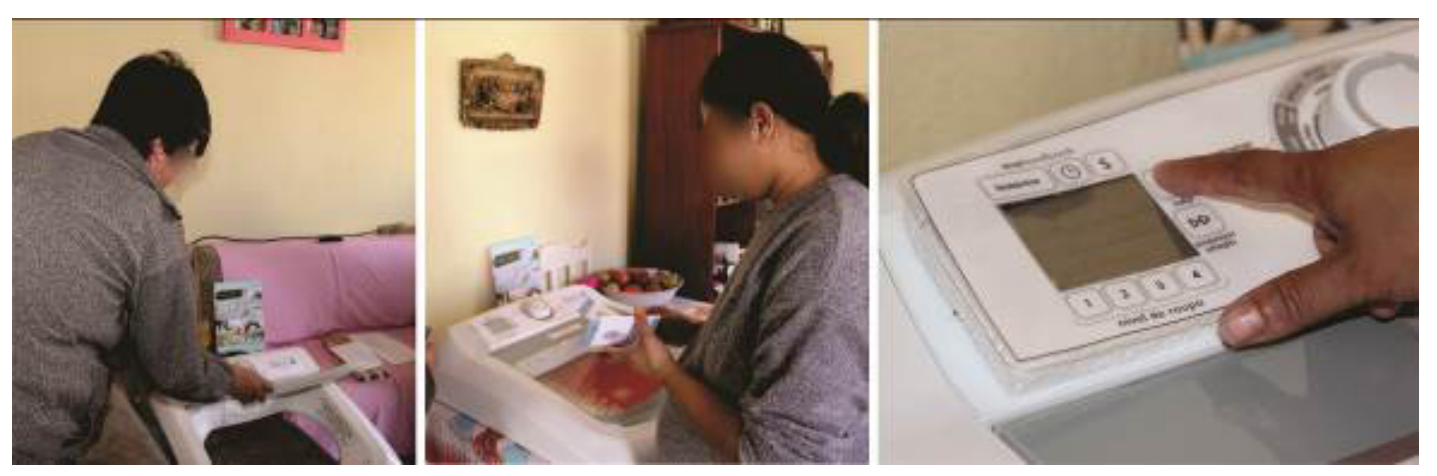

A cada feedback visualizado, os pesquisadores faziam questionamentos para estimular a usuária a percebê-los e entendê-los. Repetiu-se o teste de interação para a demonstração dos layouts 2 e 3 , respectivamente, o que contribuiu para a identificação do modelo de layout que melhor comunicava as informações do eco-feedback.

Ao final da atividade, as usuárias foram questionadas sobre o entendimento das informações disponibilizadas no eco-feedback e se lembravam-se do consumo de água, energia e tempo mostrados. Também foi explorado se elas conseguiram entender os históricos de consumo apresentados pelo eco-feedback. Procurou-se compreender ainda qual o impacto das informações de utilização no comportamento de consumo das usuárias.

Etapa 03: análise e procedimentos de avaliação dos layouts

Na simulação com o primeiro eco-feedback (figura a seguir), as usuárias se depararam com uma tela com informações disponíveis em preto e fundo cinza, com a mesma tipologia utilizada em visor de calculadora. Elas conseguiram entender as informações disponíveis na tela e conseguiram consultar todas as informações requeridas. Em alguns momentos apertavam os botões errados, sendo assim advertidas pelos pesquisadores.

Figura 7 Configuração do eco-feedback 1 (tela histórico de consumo).

\begin{tabular}{|c|c|}
\hline \multicolumn{2}{|c|}{ II HISTORICO } \\
\hline $\begin{array}{l}\text { HOJ JE BRAMCA/MS/4 } \\
\text { MOLHO CURTO/ENX. DUPLO }\end{array}$ & $\begin{array}{ll}235 & \text { LITROS } \\
0.32 \text { KUV/H } \\
0.95 \text { MinUTOS }\end{array}$ \\
\hline $\begin{array}{l}\text { ULL TIMA } \\
\text { BRANCA/S/4 }\end{array}$ & $\begin{array}{l}157 \text { LITROS } \\
0.25 \mathrm{KUW/H} \\
\text { (1) } 70 \text { MinUTTOS }\end{array}$ \\
\hline $\begin{array}{l}\text { PEMLLL TMMA } \\
\text { BRANCA/PS/4 }\end{array}$ & $\begin{array}{l}157 \text { LITROS } \\
0.16 \text { KUI/H } \\
\text { 1. } 25 \text { MiNUTOS }\end{array}$ \\
\hline
\end{tabular}


A usuária 01 obteve os seguintes equívocos: mesmo fazendo a observação do painel, a usuária ficou procurando um botão para girar ao selecionar o volume de água, porém, conseguiu identificar os botões de seleção sem a ajuda dos pesquisadores; ao acionar a função "enxágue duplo", não percebeu modificações no consumo de energia; demorou a encontrar o botão "avançar etapas"; confundiu o botão "consumo" com o "histórico de consumo"; e não havia entendido as abreviações utilizadas no layout como pouco sujo (ps), sujo (s) e muito sujo (ms). Os pesquisadores avaliaram estes erros como falta de atenção, pois a usuária fazia a leitura de forma bastante rápida. No entanto, Löbach (2001) menciona que muitas vezes erros de interação são consequências de erros de design. A usuária reportou que gostou da visualização do consumo e mencionou que sem o eco-feedback, teria que acompanhar diretamente nos medidores de água e energia.

Já a usuária 02 não soube como escolher o programa de lavagem de forma rápida, mas conseguiu sem a ajuda dos pesquisadores. Ainda, ao ser requisitado o acionamento da função "enxágue duplo", a usuária não percebeu alteração no consumo; e disse que não sabia ler a abreviação $\mathrm{Kw} / \mathrm{h}$ (quilowatt/hora), mas foi esclarecida pelos pesquisadores sobre o que significava. Para os pesquisadores, estes erros aconteceram porque a usuária não mantinha contato frequente com a lavadora de roupas automática e porque foi o primeiro contato com o eco-feedback. Outro motivo pode ser a complexidade da tipologia adotada. Ambas as usuárias conseguiram ler e entender os níveis e diferenças de consumo apresentados no histórico de consumo, ao final da simulação.

Repetindo todo o processo de simulação para o eco-feedback 2 (figura a seguir), foi evidente a redução do número de erros em comparação à primeira simulação. Utilizando um layout com padrões mais limpos, este apresentou fundo branco e letras em cinza. Havia ícones que simbolizavam água, energia, tempo, programa e etapas de lavagem e consumo. Foi utilizada uma tipologia sem serifa. Adotou-se a cor verde como padrão visual para os ícones e barras de consumo, no entanto, as barras possuíam uma gradação de cores que iniciava em verde e terminava em vermelho, indicando que o consumo aumentava à medida que o vermelho ficava mais intenso.

Figura 8 Configuração do eco-feedback 2 (tela histórico de consumo).

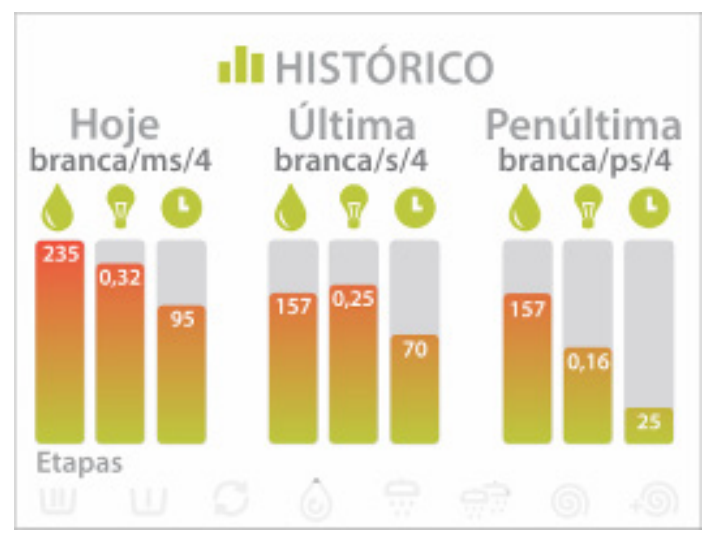


Nesta segunda simulação, a usuária 01 cometeu apenas 1 equívoco ao confundir novamente o botão "consumo" com o botão "histórico de consumo". Esta usuária também fez comentários com relação à cor dizendo que fica mais fácil de compreender; que o histórico de consumo está mais rápido de ler; e que todas as telas deste layout apresentam informações mais claras, se comparado com a primeira simulação.

A usuária 02, obteve 2 equívocos durante a simulação do processo, sendo um deles a escolha do nível 3 de roupa, onde o correto seria o nível 4; e a letra "l" que abrevia a palavra litro a deixou confusa, pois para ela parecia o número " 1 ". Ao final desta simulação, ela destacou que gostou do uso das cores e que da forma apresentada ficou mais claro identificar o maior e o menor consumo.

$\mathrm{Na}$ terceira e última simulação (figura a seguir), o eco-feedabck apresentou fundo preto e letras em cinza claro. A tipologia também foi composta por uma fonte sem serifa. Os ícones estavam representados na cor verde e cinza claro. As informações eram apresentadas em quadros e através de números. Não houve erros ou equívocos na simulação. Acredita-se que isto ocorreu porque foi utilizado o mesmo Script de simulação da tarefa para os três layouts tornando as ações conhecidas.

Figura 9 Configuração do eco-feedback 3 (tela histórico de consumo).

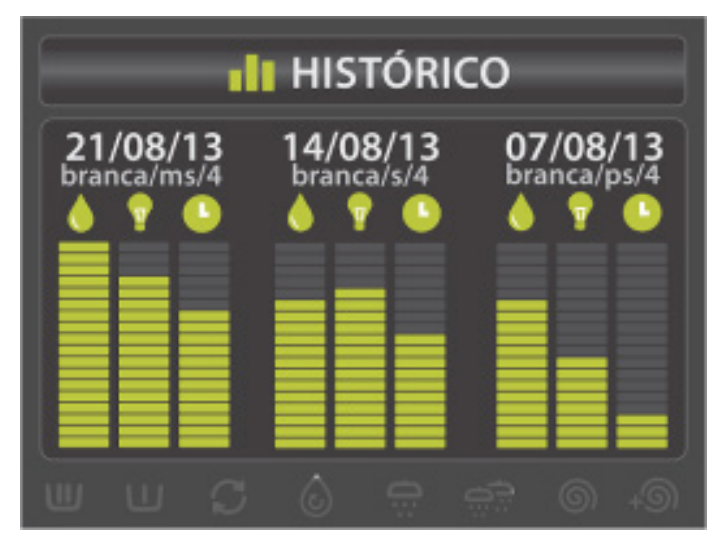

1 Foram utilizados smiles (carinhas felizes) para indicar se a programação escolhida era mais ou menos econômica. Quanto maior a economia média de água e energia na programação de lavagem, maior o sorriso do smile. Para facilitar a compreensão, foram adicionados juntamente com o smile, mensagens de estímulo.
A usuária 01 explanou que o smile 1 não estava muito claro, mas a mensagem mostrada juntamente com ele ajudou a entender que a informação a ser passada era que o processo poderia ser ainda melhor, ou seja, mais econômico. Sobre o histórico de consumo, esta usuária disse que neste layout, ela consegue fazer as comparações, mas que muita gente não conseguiria porque não há números ou indicação de níveis de consumo, somente barras.

A usuária 02 comentou sobre as dicas de economia disponibilizadas na simulação estavam claras e colaboram para a identificação de estratégias para diminuir o consumo.

Ao consultar o histórico de consumo, conseguiram entender as informações e visualizar a diferença de consumo entre os dados apresentados. Ambas conseguiram se lembrar dos feedbacks 
mostrados pela tela após a atividade. O único ponto negativo observado com relação à percepção das usuárias é que não entenderam as abreviações das categorias de sujidade das roupas: pouco suja (ps); suja (s); e muito suja (ms). Estas abreviações estavam presentes no histórico de consumo.

Ao final das atividades de interação, os pesquisadores perguntaram às usuárias se elas conseguiam se lembrar do consumo de água, energia e tempo do processo de lavagem simulado e, no histórico de consumo, qual das lavagens apresentadas havia o consumo menor. A usuária 01 errou apenas o consumo de água, pois se esqueceu de que havia selecionado o "enxágue duplo". A usuária 02 se lembrou de todos os feedbacks mostrados.

Ambas as usuárias fizeram comentários positivos e relevantes sobre os resultados apresentados, sendo os principais: o segundo ecofeedback é o que apresenta uma configuração mais compreensível, com informações mais organizadas e claras; e gostariam que algumas informações apresentassem os custos, como por exemplo, água e energia, mas disseram que da forma como foi apresentado, já são parâmetros para fazer economia no processo de lavagem.

\section{Etapa 04: feedback externo}

Um workshop foi realizado com a finalidade de apresentar e receber feedback de designers de empresa fabricante de lavadoras sobre os trabalhos realizados durante os Ciclos de Ação. Participaram deste workshop, dois colaboradores de uma empresa fabricante (A.S. e V.F.), e dois membros da equipe de pesquisadores.

Sobre o conteúdo dos eco-feedbacks, os designers da empresa fabricante reportaram que tem a percepção de que esta orientação influencia o comportamento e possibilita a economia. Para o designer V.F., esta inovação para o público em questão é também positiva para a empresa: "Se esta inovação é colocada no mercado, este consumidor, com o tempo, passa a cobrar soluções cada vez mais econômicas, o que é positivo para a empresa porque isto gera um novo campo competitivo". A designer A.S. complementa dizendo que estas inovações acabam por informar muito sobre a filosofia da empresa, ou seja, o que ela está disposta a oferecer ao usuário. O designer V.F. acrescentou sobre a iniciativa de oferecer transparência sobre o consumo: "Existe uma tendência muita forte que é fazer o consumidor conhecer mais os seus direitos, dar transparência. Hoje, isto não é um fator decisivo de compra considerado pela empresa, mas já começou a aparecer no mercado. Isto dá poder ao usuário em exigir e começar a determinar a compra”. 
O designer V.F. comentou ainda que o uso do display é o caminho mais cômodo porque oferece muitas possibilidades de inserção da informação. Para o consumidor, isto pode resultar em um acréscimo entre $R \$ 150$ e $R \$ 200$ reais. Para ele é necessário fazer uma pesquisa mais extensa e mais profunda com o público alvo. No entanto, o uso do display já está no repertório do público alvo, inclusive o de baixa renda, com o uso de dispositivos móveis como smartphones, por exemplo (DAROS, 2013).

\section{Conclusão}

A literatura mostrou que a utilização de abordagens convencionais para a mudança de comportamento, ou seja, o uso de estratégias que coloquem em prática as teorias para mudança comportamental pode conduzir a resultados satisfatórios. No entanto, o ecofeedback, utilizado nesta pesquisa apresentou potencial para redução do consumo e as próprias falas das usuárias apontaram que as mesmas estavam inclinadas à iniciar um processo de mudança de comportamento.

Através do uso do Método RITE foi possível identificar Metarequisitos que posteriormente foram desdobrados em requisitos específicos, os quais são apresentados de forma ampliada no quadro a seguir.

Quadro 1 Visão Geral dos Meta-Requisitos para Eco-feedback em Máquina de Lavar Roupa Voltada à Habitação de Interesse Social

\begin{tabular}{|c|c|}
\hline META-REQUISITOS & DESDOBRAMENTOS DOS REQUISITOS \\
\hline $\begin{array}{l}\text { PERMITIR A SINCRONIA NO PROCESSO } \\
\text { DE LAVAGEM COM OUTRAS ATIVIDADES } \\
\text { DO USUÁRIO. }\end{array}$ & $\begin{array}{l}\text { - Mostrar o tempo total e restante do } \\
\text { - } \quad \text { Ofocesso de lavagem; } \\
\text { o abastecimento do compartimento de } \\
\text { sabão e amaciante; } \\
\text { - Manter a possibilidade de interferir no } \\
\text { processo de lavagem através do avanço } \\
\text { manual de etapas; } \\
\text { - Utilizar feedback sonoro ao final do } \\
\text { processo para avisar o(a) usuário(a) do } \\
\text { status do processo. }\end{array}$ \\
\hline $\begin{array}{l}\text { AMPLIAR A PERCEPÇÃO DE CUSTO } \\
\text { ASSOCIADO AO CONSUMO. }\end{array}$ & $\begin{array}{l}\text { - } \quad \text { informar os custos ou consumo de água } \\
\text { e energia através de escalas de valor } \\
\text { ou quantidades; } \\
\text { Possibilitar a consulta de histórico de } \\
\text { consumo para comparações entre } \\
\text { programações utilizadas. }\end{array}$ \\
\hline
\end{tabular}


O Método RITE possibilitou o envolvimento do usuário desde o início da Pesquisa-ação. Suas maiores contribuições permearam a identificação de idiossincrasias da população pesquisada e o entendimento dos limites do usuário com relação à inovação do ecofeedback. O usuário participou de forma colaborativa e suas respostas ajudaram os pesquisadores a analisarem o que poderia ser melhor para o público de baixa renda. O número reduzido de participantes permitiu maior proximidade com as usuárias, possibilitando atividades com maior profundidade de análise e percepção das ações. A escolha da casa das usuárias como ambiente de realização das atividades permitiu que estas se sentissem mais a vontade e seguras diante de gravadores, câmeras e dos próprios pesquisadores. O uso da verbalização dos pensamentos e ações, o ponto chave do RITE, permitiu entender o que as usuárias estavam pensando e fazendo naquele exato momento da interação.

Segundo Modelo de Mudança de Comportamento de Grimley et al. (1997), estas usuárias já avançaram estágios para a mudança de comportamento. Antes da pesquisa permaneciam no estágio de pré-contemplação, pois não percebiam problemas no processo de lavagem de roupas. Durante os Ciclos de Ação as usuárias passaram a se estabelecer no estágio de contemplação. Neste estágio entenderam, pensaram ou mesmo sugeriram soluções para diminuir o consumo e os custos das contas de água e energia através da máquina de lavar. Segundo Froehlich (2011) e Jackson (2005), o custo apresenta forte potencial em influenciar o comportamento do usuário.

Destaca-se, enfim, que os resultados são exploratórios, havendo necessidade de novos estudos, em outros extratos da população e com amostra adequada e situações reais de uso para que os resultados sejam confirmados. Sugere-se replicar a pesquisa também para outros artefatos.

\section{Agradecimento}

Agradecemos à "empresa" pela colaboração durante a fase de campo de campo e à equipe de pesquisadores do "laboratório" da "instituição" que integraram esta pesquisa.

\section{Referências}

DAROS, C. 2013. Design para a sustentabilidade: oportunidades de inovação a partir dos hábitos de consumo na HIS. Dissertação (Mestrado). Programa de Pós-graduação em Design, Universidade Federal do Paraná, Curitiba.

DESIGN COUNCIL. 2006. RED 'Future Currents'. Disponível em: < http://www. designcouncil.org.uk/futurecurrents/index.php> [2006]. Acesso em: 15 fev. 2013. 
FALCÃO, D.M. 2009. Smart Grid e Microrredes: o futuro já é presente. Anais do VIII SIMPASE: 9-14.

FROEHLICH, J. E. 2011. Sensing and feedback of everyday activities to promote environmental behaviours. Tese (Doutorado), Department of Philosophy, Universidade de Washington, USA.

FROEHLICH, J., FINDLATER, L., \& LANDAY, J. 2010. The Design of Eco-feedback Technology. CHI 2010: 10-15, Georgia, USA.

GRIMLEY, D. M; PROCHASKA, G. E.; PROCHASKA, J. O. 1997. Condom use adoption and continuation: a transtheoretical approach. Health Education Research, v.12, n.1: 61-75.

IPEA. 2012. Nova classe média corresponde a 53\% da população. Disponível em: <http://www.ipea.gov.br/portal/index.php?option=com_ content\&view=article $\&$ id $=15558>$. Acesso em 20 mar. 2013.

JACKSON, T. 2005. Motivating Sustainable Consumption: a review of evidence on consumer behaviour and behavioural change. In: A report to the Sustainable Development Research Network as part of the ESRC Sustainable Technologies Programme Center for Environmental Strategy, University of Surrey, Guildford.

KOLB. D. A. 1978. Psicologia organizacional: uma abordagem vivencial. São Paulo: Atlas.

LILLEY, D., \& LOFTHOUSE, V. 2009a. Teaching Ethics For Design For Sustainable Behaviour: A pilot study. Design and Technology Education: An International Journal. v.15, n.2: 55-68.

LILLEY, D., \& LOFTHOUSE, V. 2009b. Sustainable design education: considering design for behavioural change. Engineering education, v. 4(1): 29-41.

LOCKTON, D.; HARRISON, D.; STANTON, N. A. 2009. Design for Sustainable Behaviour: investigating design methods for influencing user behaviour. Sustainable innovation: 26-27.

MEDLOCK, M.C.; WIXON, D.; TERRANO, M.; ROMERO, R. L.; FULTON, B. 2002. Using the RITE method to improve products: a definition and a case study. In: <http://www.microsoft.com/en-us/download/details.aspx?id=20940> .

NORMAN, Donald A. 2007. O design do futuro. Rio de Janeiro: Rocco.

SKOON. Projeto Skoon. 2014. Disponível em: < http://projeto-skoon.blogspot.com. br/?zX=b8cec51b89b674f5>. Acesso em 20 jan. 2014.

TANG, T., \& BHAMRA, T. 2008a. Understanding Consumer Behaviour to Reduce Environmental Impacts through Sustainable Product Design, Loughborough University Loughborough, Reino Unido.

TANG, T., \& BHAMRA, T. A. 2008b. Changing Energy Consuption Behaviour throungh sustainable product design, Loughborough University. Loughborough, Reino Unido. 


\section{Sobre os autores}

\section{Marcelo dos Santos Forcato}

Mestre, Universidade Estadual de Maringá - UEM. É professor do Departamento de Design e Moda da UEM e ministra aulas no curso de Design da mesma universidade. Atua na área de pesquisa do design para a sustentabilidade e desenvolvimento em design de mobiliário. $<$ marcelo.forcato@gmail.com>

\section{Aguinaldo dos Santos}

Pós-doutor, Universidade Federal do Paraná - UFPR, é bolsista produtividade nível 2 do CNPq, professor adjunto do Departamento de Design da UFPR e sua área de atuação inclui a lean production e o design para a sustentabilidade tendo como objeto de pesquisa principal a habitação de interesse social e sistemas produto+serviço. <asantos@ufpr.br>

Artigo recebido em 15 out. 2014, aprovado em 09 ago. 2015. 